\title{
Pulmonary microvascular permeability in patients with severe mitral stenosis
}

\author{
S W Davies, P Wilkinson, J Keegan, J Bailey, A D Timmis, J A Wedzicha, R M Rudd
}

\begin{abstract}
Patients with rheumatic mitral stenosis often have no pulmonary oedema despite considerably increased pulmonary venous pressure. Pulmonary microvascular permeability was measured noninvasively by a previously validated method of double isotope scintigraphy with indium-113m and technetium-99m. This permits calculation of an index reflecting transferrin efflux and thus, indirectly, the microvascular permeability. Fifteen patients with severe mitral stenosis (defined as valve area $<1.0 \mathrm{~cm}^{2}$ ) were compared with a control group of 11 patients with mild coronary artery disease. The permeability index was significantly lower in patients with mitral stenosis than in the control group. Furthermore, the extent of reduction of the permeability index correlated with the severity of mitral stenosis as reflected by the Gorlin valve area.

This finding may account for the relative resistance of these patients to pulmonary oedema despite chronic pulmonary venous hypertension.
\end{abstract}

Patients with mitral stenosis have a surprising resistance to pulmonary oedema despite persistently increased pulmonary venous pressure, and pulmonary oedema may only appear terminally or as a complication of fast atrial fibrillation. ${ }^{1}$ In patients with myocardial infarction, a rapid increase in pulmonary venous pressure to $>20 \mathrm{~mm} \mathrm{Hg}$ (measured from midchest level) results in the formation of pulmonary oedema. ${ }^{23}$ In patients with mitral valve disease, however, pulmonary venous pressure can rise gradually to $\geqslant 30 \mathrm{~mm} \mathrm{Hg}$ without the development of overt pulmonary oedema $a^{4}$-though women with mild or moderate mitral stenosis (valve area $>1.5$ $\mathrm{cm}^{2}$ ) in whom acute pulmonary oedema develops during pregnancy are a possible exception.

Two main hypotheses have been advanced to explain this resistance to pulmonary oedema in patients with mitral stenosis. First, a decrease in pulmonary microvascular permeability might be the protective mechanism. Alternatively pulmonary oedema might be prevented by increased lymphatic flow, capillary permeability being normal or even increased as a result of vascular damage. To investigate these hypotheses we estimated pulmonary microvascular permeability by the non-invasive technique of double isotope scintigraphy, first described by Gorin et $a l^{6}$ and subsequently modified by Basran et al. ${ }^{7}$ In invasive experiments in sheep, the plasma protein accumulation index thus obtained closely paralleled the concentration of protein measured in the lymph draining from the lung. ${ }^{6}$ The plasma protein accumulation index therefore provides a non-invasive measure of pulmonary microvascular permeability and we used it in the present study to examine the hypothesis that resistance to pulmonary oedema in mitral stenosis is the result of decreased pulmonary microvascular permeability.

\section{Patients and methods \\ PATIENTS}

The study was approved by the local ethics committee and all subjects gave their written consent. We studied 15 patients undergoing cardiac catheterisation for the assessment of longstanding mitral stenosis. Each had had moderate to severe exertional dyspnoea (Canadian Cardiovascular Society grade 2 or 3) for 4-14 years. Patients had either pure mitral stenosis or dominant mitral stenosis with mild mitral regurgitation, and in all of them the valve area calculated by the Gorlin formula was $<1.0 \mathrm{~cm}^{2}$. The diagnosis of rheumatic stenosis was based on a history of past rheumatic fever and the typical $M$ mode echocardiographic features of leaflet thickening and commissural fusion. There was no other valve disease or cardiac abnormality and no evidence of primary lung disease.

We measured the plasma protein accumulation in 11 patients who had mild or moderate coronary artery disease with normal left ventricular function, as judged by ventriculography and normal left ventricular end diastolic pressure ( $<10 \mathrm{~mm} \mathrm{Hg}$ ). M mode and cross sectional echocardiography were normal in all of them. Six of these were smokers (5-10 cigarettes per day) but all had normal lung function tests and no evidence of primary lung disease.

\section{PROTOCOL}

Before cardiac catheterisation each patient underwent full clinical assessment, electrocardiogram, chest $x$ ray, and echocardiography. Lung function testing included spirometry, single-breath carbon monoxide diffusing capacity measurements $\left(\mathrm{DL}_{\mathrm{CO}}\right.$ and $\mathrm{K}_{\mathrm{CO}}$ ), and plethysmographic lung volume measurements. In 10 of the patients with 
Table 1 Baseline cardiopulmonary data (median (range)) in controls and patients with mitral stenosis

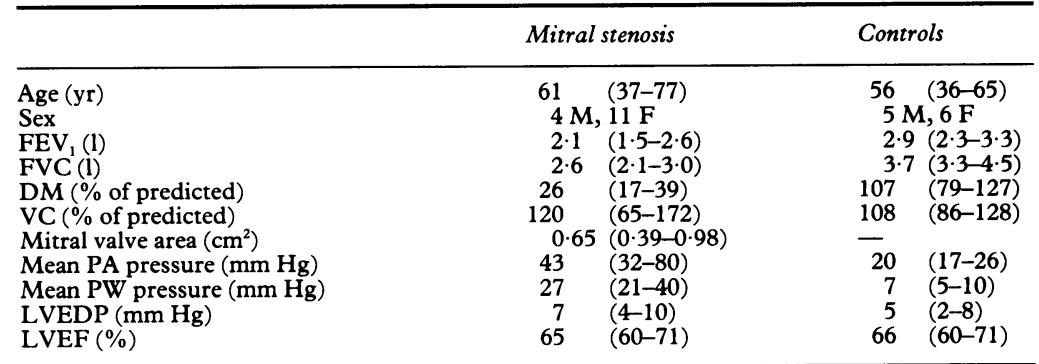

DM, diffusing conductance; $\mathrm{FEV}_{1}$, forced expiratory volume in one second; FVC, forced vital capacity; LVEDP, left ventricular end diastolic pressure; LVEF, left ventricular ejection fraction; VC, capillary blood volume; PA, pulmonary artery; PW, pulmonary capillary wedge.

mitral stenosis and in eight of the controls the diffusing conductance (DM) of the alveolarcapillary membrane and the accessible pulmonary capillary blood volume (VC) were determined by the method of Roughton and Forster, ${ }^{8}$ and $\mathrm{K}_{\mathrm{co}}$ was measured at oxygen saturations of $21 \%$ and $100 \%$.

\section{SCINTIGRAPHY}

Pulmonary microvascular permeability was assessed by measuring the plasma protein accumulation index, which is based on the pulmonary accumulation of radiolabelled transferrin (molecular weight 88000 ). This was measured by external radiation detectors, and by correcting for any changes in circulating blood volume by simultaneously monitoring radiolabelled autologous red blood cells. A modification of the protocols of Gorin ${ }^{6}$ and Basran $^{7}$ was used to label transferrin in vivo by intravenous injecton of $100 \mathrm{MBq}$ of indium-113m chloride solution from a sterile generator. Red blood cells were labelled in vivo by the intravenous injection of $0.02 \mathrm{mg}$ per kg body weight of stannous fluoride with $0.024 \mathrm{mg}$ per $\mathrm{kg}$ body weight of sodium medronate, and then after a delay of $15 \mathrm{~min}$ utes, $100 \mathrm{MBq}$ of technetium-99m pertechnetate from a sterile generator. After these intravenous injections, count rates from both radionuclides were monitored in the supine patient by a large single-crystal gamma camera placed posteriorly under the thorax and a portable probe over the anterior chest wall. The probe acquired data from an area approximately $8 \mathrm{~cm}$ in diameter and was placed alternately over the cardiac area and the right upper zone. The duration of scanning necessary for significant results was 90 minutes.

ANALYSIS

The ratio of indium-113m activity to technetium-99m activity was calculated for each area, after correction for down-scatter from indium $393 \mathrm{keV}$ to the technetium window $141 \mathrm{keV}$. This ratio counted over the lung fields was then divided by the same ratio counted over the cardiac area, and the overall quotient was plotted against time. The plasma protein accumulation index is defined as the slope of this relation and reflects transferrin efflux and accumulation in the lung fields. ${ }^{67}$ The slope of the best-fit straight line was determined by computed linear regression analysis according to the method of least squares.

A regional image of plasma protein accumulation index was obtained from the gamma camera data; each pixel corresponded to a square of side $12 \mathrm{~mm}$ on the thorax of the patient. By defining regions of interest corresponding to each lung, all enclosed pixels were averaged to obtain a mean plasma protein accumulation index for the individual patient.

Distribution-free statistics have been used throughout. Values are given as median \pm semi-interquartile range, patient groups were compared but the Mann-Whitney U statistic, and correlations were examined by the Spearman rank correlation coefficient $R$.

\section{Results}

\section{GROUP CHARACTERISTICS}

We studied 15 patients with mitral stenosis (four men and 11 women, aged 37-77 (median $62)$ ). The five men and six women in the control group were aged 36-65 (median 56). The patients with mitral stenosis were thus slightly older than the controls, and, as expected, were predominantly female. All were in established atrial fibrillation, unlike the controls all of whom were in sinus rhythm.

\section{LUNG FUNCTION}

As expected the patients with severe mitral stenosis had reduced lung volumes (table 1 ). The results for diffusing conductance of the alveolar-capillary membrane and for the accessible pulmonary capillary blood volume showed a wide range of values and in this small group of patients were not related to age, sex, or severity of mitral stenosis.

\section{HAEMODYNAMIC VARIABLES}

Left ventricular function as reflected by ejection fraction and end diastolic pressure was similar in the two groups (table 1). The patients with mitral stenosis all had a considerable increase in mean pulmonary artery wedge pressure to between 21 and 40 $\mathrm{mm} \mathrm{Hg}$. The mean mitral valve gradient for 10 cycles was between 8 and $18 \mathrm{~mm} \mathrm{Hg}$, reflecting critical reductions in calculated

Table 2 Plasma protein accumulation (PPA) index results

\begin{tabular}{|c|c|c|c|c|}
\hline \multirow[b]{2}{*}{ Group } & \multirow[b]{2}{*}{ No } & \multicolumn{3}{|c|}{$P P A$ index $\left(\times 10^{-3}\right)$ per minute } \\
\hline & & Maximum & Minimum & $\begin{array}{l}\text { Median ( } \pm \text { semi-interquartile } \\
\text { range) }\end{array}$ \\
\hline $\begin{array}{l}\text { Severe mitral stenosis } \\
\text { Controls }\end{array}$ & $\begin{array}{l}15 \\
11\end{array}$ & $\begin{array}{l}+0.30 \\
+1 \cdot 00\end{array}$ & $\begin{array}{l}-1 \cdot 70 \\
-0 \cdot 25\end{array}$ & $\left.\begin{array}{r}0.0 \pm 0.27 \\
+0.3 \pm 0.32\end{array}\right\} \quad p<0.02$ \\
\hline
\end{tabular}


Figure 1 Examples of regional plasma protein accumulation images in (B) a patient with severe mitral stenosis. (A) a control subject and

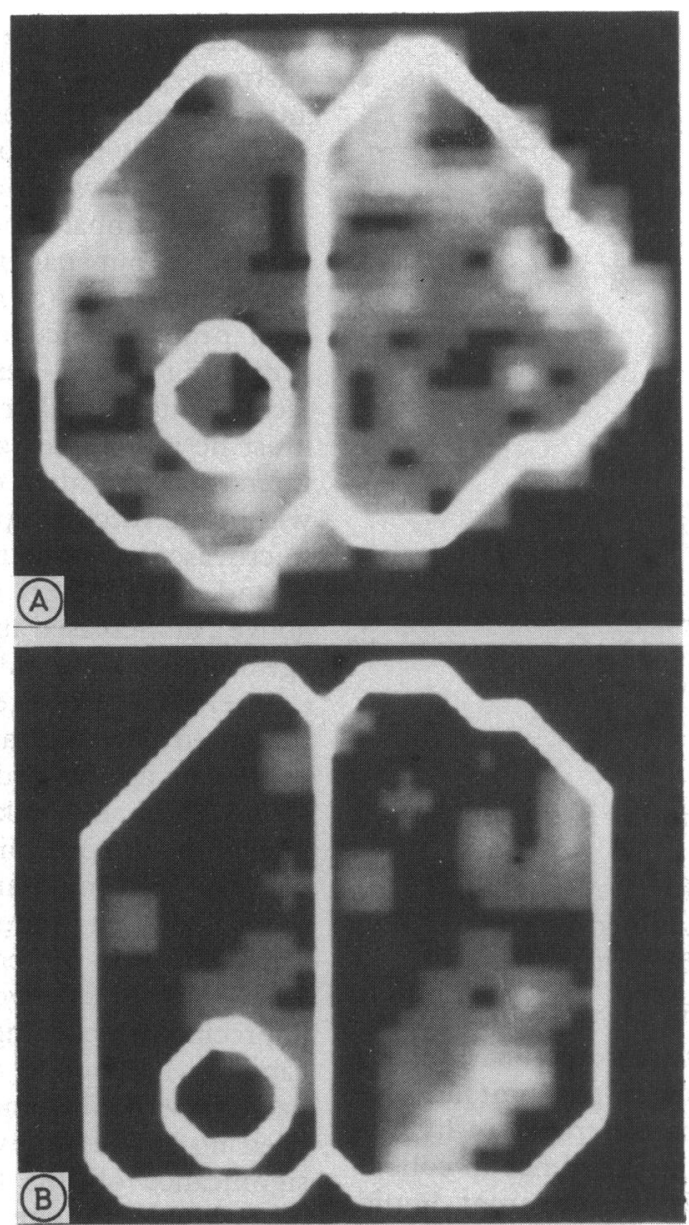

valve area (formula of Gorlin and Gorlin) which was $<1.0 \mathrm{~cm}^{2}$ in every patient. In most there was also mitral regurgitation-mild (grade 1) in nine patients but moderate (grade 2 or 3 ) in four. Eleven of the patients subsequently underwent mitral valve replacement.

\section{PULMONARY MICROVASCULAR PERMEABILITY} Figure 1 shows examples of the regional images of plasma protein accumulation index throughout both lung fields. In the controls (without mitral valve disease or left ventricular impairment) there was considerable variation from

Figure 2 Mean plasma protein accumulation index for individual patients.

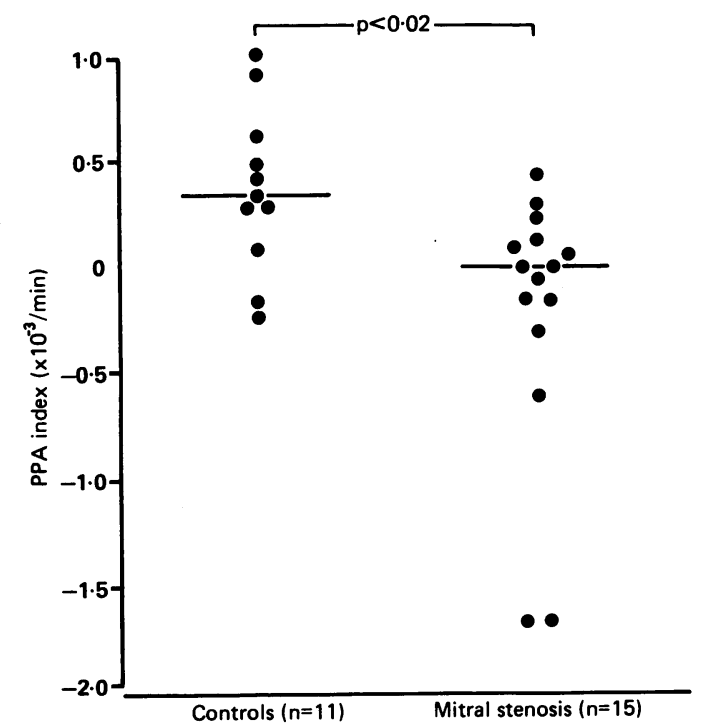

pixel to pixel, but no consistent regional pattern, and this is attributed to the low absolute number of counts from each small pixel area resulting in noise. In the patients with mitral stenosis there was again some heterogeneity in the image but no regional pattern; the average pixel values were lower than in the controls, as is apparent from fig 1 . This difference between the groups is confirmed by calculation of the mean plasma protein accumulation index of the lung fields in each individual patient (fig 2). Though there was a wide range of individual plasma protein accumulation values in each group and considerable overlap between the groups, the difference between the group medians was significant $(p<0.02)$. Moreover, within the mitral stenosis group the mean plasma protein accumulation index and the severity of mitral stenosis as reflected by the Gorlin mitral valve area were strongly correlated $(R=+0.7, p<0.01)$ (fig 3$)$.

There were no significant correlations between the plasma protein accumulation index and any other haemodynamic or lung function variables. In particular there was a trend towards correlation with the mean pulmonary wedge pressure (fig 4) that did not attain statistical significance.

\section{Discussion}

The patients with mitral stenosis included in this study all had severely reduced valve areas, but despite significant increases in pulmonary artery wedge pressures and dilatation of the upper lobe veins none had radiographic evidence of interstitial pulmonary oedema. In this study we used a previously validated double isotope scintigraphic method to evaluate pulmonary microvascular permeability non-invasively in these patients. Regional images and mean values of an index of ${ }^{113 \mathrm{~m} I n-l a b e l l e d}$ transferrin accumulation in the lung over a 90 minute period gave an indirect measure of plasma transferrin efflux-the plasma protein accumulation index-reflecting the microvascular permeability. The data showed that in severe mitral stenosis the plasma protein accumulation index was significantly less than in controls with normal mitral valves and normal left ventricular function. Furthermore, the degree to which the plasma protein accumulation index was reduced correlated closely with the severity of mitral stenosis as judged by the calculated valve area. The patient and control groups were of comparable age, but there were more women in the patient group.

We found a wide range of values of the mean plasma protein accumulation index for the individuals within each group and considerable overlap between the groups (fig 2 ). In some subjects the detected counts showed considerable fluctuation during the acquisition period, and when linear regression was used to find the best-fit straight line, the result was a negative plasma protein accumulation index. We attribute this to the high noise-to-signal ratio of this dual isotope method; our range of values in 
Figure 3 Relation between plasma protein accumulation index and the severity of mitral stenosis.

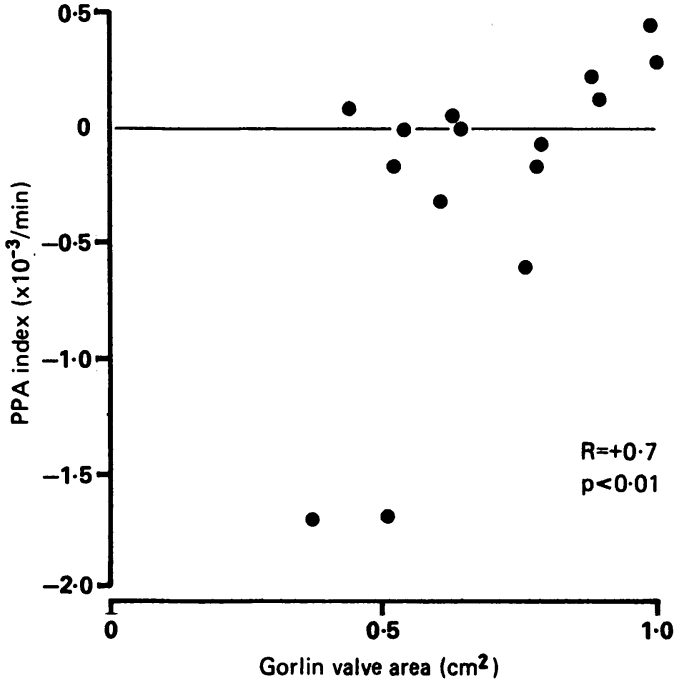

the control group was similar to those reported by other workers. ${ }^{79}$

Factors affecting the formation of pulmonary interstitial fluid are described by the Starling equation, ${ }^{10}$ which may be written:

$$
\mathrm{F} / \mathrm{A}=\mathrm{K}(\Delta \mathbf{P}-\mathrm{s} . \Delta \Pi)
$$

where $F / A$ is the net rate of flow from capillary lumen to interstitial space per unit area of capillary wall, $\Delta \mathrm{P}$ is the difference in hydrostatic pressure, $\Delta \Pi$ is the difference in colloid osmotic pressure, $K$ is the apparent liquid filtration coefficient (hydraulic conductivity), and $s$ is the reflection coefficient for colloids at the capillary wall. The pulmonary capillary hydrostatic and osmotic pressures are relatively easily estimated (as pulmonary wedge pressure and plasma colloid osmotic pressure) and their independent influences on the development of pulmonary oedema are now well established. ${ }^{112}$ The other terms are difficult to measure non-invasively in humans but may be equally important in determining pulmonary oedema. Changes in pulmonary microvascular permeability have been postulated in cases of pulmonary oedema related to hypoxia, ${ }^{13}$ adult respiratory distress syndrome, ${ }^{14}$ pulmonary embolism, ${ }^{15}$ and lung re-expansion. ${ }^{16}$ Indirect evidence of capillary permeability changes in pulmonary and renal beds has recently been

\footnotetext{
Figure 4 Lack of relation between plasma protein accumulation index and the mean pulmonary capillary wedge pressure.
}

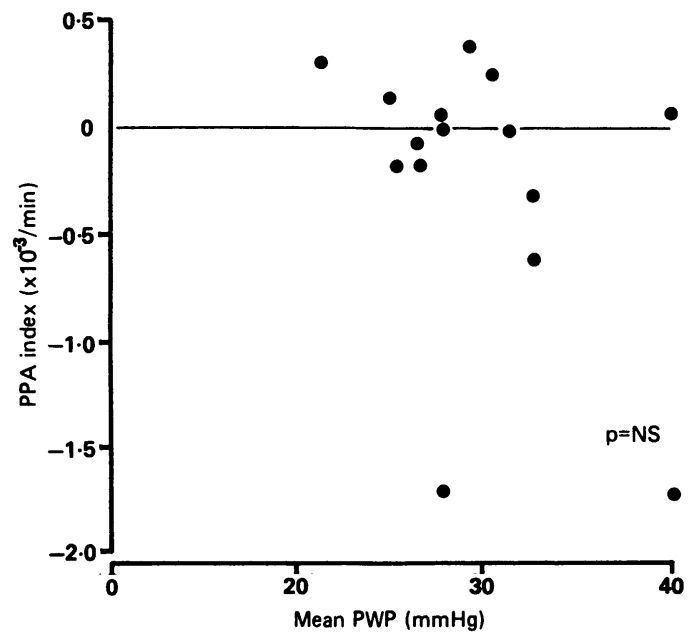

reported in patients with adult respiratory distress syndrome. ${ }^{17}$ Increased pulmonary microvascular permeability was measured more directly in animal studies when pulmonary oedema was induced by haemorrhagic shock or by inhaled or circulating toxins. ${ }^{18-20}$

Because our patients had normal plasma oncotic pressures (as reflected by albumin and total protein concentrations) the mechanism protecting against pulmonary oedema in the face of high capillary hydrostatic pressures must lie in complex alterations in pulmonary interstitial pressures favouring fluid retention within the vascular space, reduced pulmonary microvascular permeability (embraced by the $\mathbf{K}$ and $\mathbf{s}$ parameters in the Starling equation above), or increased and rapid lymphatic drainage of interstitial fluid.

Interstitial pressures in the lung cannot be measured clinically and their role, if any, in protecting against oedema formation in mitral stenosis remains unknown. Direct measurement of pulmonary microvascular permeability has also been impossible but it has long been suspected that reductions in permeability might be the protective mechanism. Since 1936, numerous investigators have reported appreciable thickening of the layer between the capillary lumen and the alveolar gas space in patients with mitral stenosis, ${ }^{21-23}$ but there have been no studies to evaluate the physiological significance of this histological observation. The double isotope scintigraphic technique developed by Gorin ${ }^{6}$ and modified for use in patients by Basran ${ }^{7}$ is a non-invasive method that is ideally suited to this purpose. Our finding that the plasma protein accumulation index in patients with mitral stenosis was significantly less than in controls suggests that the rate of transferrin efflux was reduced by parallel reductions in pulmonary microvascular permeability.

The changes in the pulmonary microcirculation in mitral stenosis have attracted much attention, and the explanation of the resistance to pulmonary oedema has been the subject of debate. ${ }^{24-26}$ Though the Starling equation describes the principal determinants of fluid flux across the capillary wall, the level of interstitial fluid also depends on the dynamics of lymphatic flow draining protein and fluid back into the circulation. Thus increased lymphatic flow might protect against pulmonary oedema. Indeed, there was histological evidence of dilated pulmonary lymphatic vessels in biopsy material from patients with chronically raised left atrial pressure. ${ }^{27} 28$ Moreover, in animal models of chronic pulmonary venous hypertension, considerable increases in pulmonary lymphatic flow were reported ${ }^{29}$ though the correlation with lung water was generally poor. ${ }^{30}$

Does our finding of a reduced plasma protein accumulation index in severe mitral stenosis reflect rapid clearance of the radiotracer in a hyperdynamic lymphatic system, rather than altered pulmonary microvascular permeability? This interpretation of our data is not supported by the original animal experiments in which double isotope scintigraphy was used 
to examine protein fluxes in the lung. ${ }^{\circ}$ In these experiments it was found that the plasma protein accumulation index closely paralleled the protein concentrations in pulmonary lymph (and thus pulmonary microvascular permeability) rather than the volume of lymphatic flow. Based on these data, the reduction in plasma protein accumulation index in our patients with severe mitral stenosis indicates reduced pulmonary microvascular permeability rather than increased lymphatic clearance.

\section{CONCLUSIONS}

Pulmonary microvascular permeability, as measured by the plasma protein accumulation index of transferrin efflux, was significantly reduced in severe mitral stenosis. Furthermore, the extent of this reduction correlated with the severity of the mitral stenosis, as reflected by the calculated valve area. The resistance to pulmonary oedema of patients with severe rheumatic mitral stenosis may at least in part be attributable to a decrease in pulmonary microvascular permeability. It is, however, likely that other mechanisms also contribute, such as increased left atrial size and compliance and increased pulmonary lymphatic drainage.

1 Wood P. An appreciation of mitral stenosis. $\mathrm{Br} \mathrm{Med} \mathrm{J}$ 1954;i:1051-63 and 1113-24.

2 Lassers BW, George M, Anderton JL, et al. Left ventricular failure in acute myocardial infarction. Am J Cardiol 1970;25:511-22.

3 Forrester JS, Diamond G, McHugh TJ, Swan HJC. Filling pressures in the right and left sides of the heart in acute myocardial infarction. N Engl J Med 1971;285:190-3.

4 Davies LG, Goodwin JF, Van Leuven BD. The nature of pulmonary hypertension in mitral stenosis. Br Heart $J$ 1954;16:440-6.

5 Dexter L. Physiologic changes in mitral stenosis. $N$ Engl $J$ Med 1956;254:829-30.

6 Gorin AB, Weidner WJ, Demling RJ, Staub NC. Noninvasive measurement of pulmonary transvascular protein invasive measurement of pulmonary transvasc
flux in sheep. $J$ Appl Physiol 1978;45:225-33.

7 Basran GS, Byrne AJ, Hardy JG. A noninvasive technique for monitoring lung vascular permeability in man. Nucl Med Commun 1985;3:3-10

8 Roughton FJW, Forster RE. Relative importance of diffusion and chemical reaction rates in determining rate of exchange of gases in the human lung. $J$ Appl Physiol 1957;11:290-302.
9 Braude S, Nolop KB, Hughes JMB, et al. Comparison of lung vascular and epithelial permeability indices in the adult respiratory distress syndrome. Am Rev Respir Dis 1986;133:1002-5.

10 Michel CC, Clough G. Capillary permeability and transvascular fluid balance. In: Sleight P, Jones JV, eds. Scientific cular fluid balance. In: Sleight P, Jones JV, eds. Scientific foundations

11 Guyton A, Lindsey AW. Effect of elevated left atrial pressure and decreased plasma protein concentration on the development of pulmonary oedema. Circ Res 1959;7:649-57.

12 DaLuz PL, Shubin H, Weil MH, et al. Pulmonary oedema related to changes in colloid osmotic and pulmonary artery wedge pressure in patients after acute myocardial infarction. Circulation 1975;51:350-7.

13 Robin ED, Cross CE, Zelis R. Pulmonary oedema (second of two parts). N Engl J Med 1973;288:292-304.

14 Bachofen M, Bachofen H, Weibel E. Lung oedema in the adult respiratory distress syndrome. In: Fishman AP and Wilkins, 1979:241-52.

15 Staub NC, Ohkuda K, Nakahara $K$, et al. Effects of microemboli on lung fluid balance in anaesthetised sheep. microemboli on lung fluid balan

16 Pavlin JD, Nessly ML, Cheney FW. Increased pulmonary vascular permeability as a cause of re-expansion pulmonary oedema in rabbits. Am Rev Respir Dis 1981;124:422-7.

17 Tennenberg SD, Jacobs MP, Solomkin JS, Ehlers NA Hurst JM. Increased pulmonary alveolar-capillary permeability in patients with adult respiratory distress syndrome. Crit Care Med 1987;15:289-93.

18 Moss GS, Das Gupta TK, Newson B, Nyhus LM. Morphologic changes in the primate lung after haemorrhagic shock. Surg Gynecol Obstet 1972;134:3-9.

19 Cameron GR, Courtice FC. The production and removal of oedema fluid in the lungs after exposure to carbonyl chloride (phosgene) J Physiol (Lond) 1946;105:175-85.

20 Snell JD Jr, Ramsey LH. Pulmonary oedema as a result of endotoxaemia. Am J Physiol 1969;217:170-5.

21 Parker F, Weiss S. The nature and significance of the structural changes in the lungs in mitral stenosis. $A m \mathrm{~J}$ Ptructural changes in

22 Heath D, Edwards FR. Histological changes in the lung in diseases associated with pulmonary venous hypertension. Br J Dis Chest 1959;53:8-18.

23 Kay JM, Edwards FR. Ultrastructure of the alveolar capillary wall in mitral stenosis. J Pathol 1973;111:239-45.

24 Gorlin R, Lewis BM, Haynes FW, Spiegel RJ, Dexter L. Factors regulating pulmonary capillary pressure in mitral stenosis. Am Heart J 1951;41:834-54.

25 Dalen JE, Alpert JS. Valvular heart disease. Boston: Little, Brown, 1981

26 Harris P, Segel N, Bishop JM. The relation between pressure and flow in the pulmonary circulation in normal subjects and in patients wth chronic bronchits and mitral stenosis. Cardiovasc Res 1968;2:73-83.

27 Heath $D$, Hicken $P$. The relation between left atrial hypertension and lymphatic distension in lung biopsies. Thorax 1960;15:54-8.

28 Wagenvoort CA, Wagenvoort N. Pathology of pulmonary hypertension. 2nd ed. New York: John Wiley and Sons,
hond

29 Uhley HN, Leeds SE, Sampson JJ, Friedman M. Role of pulmonary lymphatics in chronic pulmonary oedema. Circ Res 1962;11:966-70.

30 Brigham KL. Lung lymph composition and flow in experimental pulmonary oedema. In: Fishman AP, Renkin EW, eds. Pulmonary edema. Bàltimore: Williams and Wilkins, 1979:161-73. 